\title{
Antioxidant Silver-based Biogenic Systems Generated from Arctium lappa Leaves
}

\author{
MARCELA ELISABETA BARBINTA-PATRASCU ${ }^{1}$, DANIELA BESLIU², \\ AURELIA MEGHEA ${ }^{2 *}$ \\ ${ }^{1}$ University of Bucharest, Faculty of Physics, Department of Electricity, Solid-State Physics and Biophysics, \\ 405 Atomistilor Str., 077125, Bucharest-Magurele, Romania \\ ${ }^{2}$ University Politehnica of Bucharest, Faculty of Applied Chemistry and Materials Science, Department of Inorganic \\ Chemistry, Physical Chemistry and Electrochemistry, 1-7 Polizu Str., 011061, Bucharest, Romania
}

\begin{abstract}
This work aims at designing through a "green" bottom-up strategy, four types of bio-based systems containing artificial cell membranes (with or without vitamin $C$ ) and silver nanoparticles (AgNPs) phyto-generated from aqueous extract of Arctium lappa leaves. The "green" approaches for AgNP synthesis, by using the vast bioreducing potential of plants are low-cost and eco-friendly procedures.Exploiting vegetal wastes as precursors for phyto-metallic nanoparticles has received attention from scientific community in the last years due to its significant economic and environmental impacts. UV-Vis absorption spectra demonstrated the biosynthesis of metallic nanoparticles which exhibited a strong SPR peak located at $437 \mathrm{~nm}$ wavelengths. The formation of the biocomposites containing the "green" synthesized AgNPs has been demonstrated by UV-Vis absorption spectroscopy and Dynamic Light Scattering measurements. DLS results highlighted the nanoscale size of the prepared "green" AgNPs. The physical stability of the obtained silver-based systems was evaluated through zeta potential values, based on electrophoretic mobility. The systems loaded with vitamin $C$ proved to be more stable and showed enhanced antioxidant activities (between $72.3 \%$ to $88 \%$ evaluated by chemiluminescence technique). Our results demonstrated that these developed silverbased biogenic systems generated from Arctium lappa leaves could be used as antioxidant agents in various biomedical applications.
\end{abstract}

Keywords: burdock-nanosilver, bio-inspired membranes, vitamin $C$, antioxidant activity.

\section{Introduction}

This work develops a "green" bottom-up strategy to achieve antioxidant delivery systems based on vitamin $\mathrm{C}$, biomimetic membranes (liposomes) and biogenic nano-silver synthesized from Arctium lappa leaves aqueous extract. Liposomes are self-assembling vesicles containing one or more lipid bilayers with a unique structure (similar to the structure of biological membranes) conferring them the ability to load both hydrophilic and lipophilic compounds, and also some other interesting properties such as: protection of active agents [1,2], building block for optoelectronic devices [3], and also enhanced stability and improved biological properties (such as: antioxidant, antimicrobial and antiproliferative activities) for silver-based composites [4-7]. The ,green” synthesis of silver nanoparticles using aqueous vegetal extracts is a rapid eco-friendly technique which implies three stages: (i) reduction of silver ions; (ii) growth of AgNPs, and (iii) stabilization of developed metallic nanoparticles [8]. „Green” synthesized silver nanoparticles are recognized for their interesting biological activities. Thus, recent researches summarizes the antioxidant properties of AgNPs phytosynthesized from aqueous extract of Glycyrrhiza glabra (licorice, sweet wood) [9], cloves [4, 10] and Citrus peels [5, 11, 12]. The incorporation of AgNPs in polyurethane nanovesicles [13], liposomes $[7,14]$, or phytosomes [6] resulted in biocomposites with enhanced biological performances.

*email: a.meghea@gmail.com; aurelia.meghea@upb.ro 
In this study, the silver nanoparticles were phytosynthesized from Arctium lappa (known as burdock), a popular plant widely used in treatment of hepatitis, atherosclerosis, hypertension, geriatric diseases due to their polyphenolic constituents with antioxidant properties [15]. This wild plant was chosen due to its valuable bio-activities and therapeutic effectiveness, and also due to economic reasons, taking into account that burdock is one of the most widespread plant in our country, Romania. Valorization of our natural resources, in a "green" manner, is a good idea to keep clean the environment.

Barbinta-Patrascu and co-workers evaluated the antioxidant activity of AgNPs (obtained by "green synthesis" using edible plants) through chemiluminescence technique and ABTS $\cdot^{+}$method, demonstrating that phytosynthesized silver nanoparticles exhibit superior activity of capturing shortlived free radicals compared to long-lived free radicals [16]. The antioxidant activity of the composites bio-developed in the present study was estimated by chemiluminescence assay - which is a rapid method of testing the ability to capture the short-lived free radicals [17-19]. The novelty of our study is the incorporation of AgNPs into liposomes with vitamin $\mathrm{C}$ that increases their bioactivity and stability; the developed biocomposites can serve as «building blocks» for the development of new bio-active materials that have a high potential for applicability in the biomedical field. Vitamin $\mathrm{C}$ or ascorbic acid is an antioxidant molecule which prevents and scavenges the formation of reactive oxygen species [20], while its incorporation in liposomes significantly improves their properties and applications [21]. The developed silver-based biocomposites were characterized by UV-Vis absorption spectroscopy and Dynamic Light Scattering measurements; their physical stability was estimated through zeta potential measurements, and the antioxidant properties by chemiluminescence technique. The presence of silver nanoparticles and of vitamin $\mathrm{C}$ in biocomposites was demonstrated by UV-Vis absorption spectra.

\section{Materials and methods}

\subsection{Materials}

$\mathrm{L}(+)$ Ascorbic acid (vitamin C), $\mathrm{KH}_{2} \mathrm{PO}_{4}, \mathrm{Na}_{2} \mathrm{HPO}_{4}$, tris (hydroxymethylaminomethane base), $\mathrm{HCl}$, $\mathrm{H}_{2} \mathrm{O}_{2}$, luminol (5-amino-2,3-dihydro-phthalazine-1,4-dione), were procured from Merck (Germany). Soybean lecithin and $\mathrm{NaCl}$ were supplied by Sigma Aldrich (Germany), and silver nitrate from Gatt Koller - GmbH Austria. The burdock leaves were purchased from a local Romanian garden in Ilfov county.

\subsection{Methods}

\subsubsection{Bio-Preparation of silver nanoparticles from burdock extract}

An amount of $40 \mathrm{~g}$ fresh leaves of Arctium lappa harvested in June month, in Ilfov county, were inserted into $210 \mathrm{~mL}$ boiling water and kept in there for 15 minutes. After cooling, this mixture was filtered through Whatman paper no. 1, resulting in a clear burdock extract (sample BE). A volume of $300 \mu \mathrm{L}$ of this extract was added into $30 \mathrm{~mL}$ of $1 \mathrm{mM} \mathrm{AgNO}_{3}$ solution, and the resulted solution was continuously stirred for $24 \mathrm{~h}$; the colour turned from pale yellow to reddish brown after $40 \mathrm{~min}$., highlighting the formation of silver nanoparticles (sample nS).

\subsubsection{Preparation of bio-inspired membranes}

The biomimetic membranes were obtained by hydration of a thin film of soybean lecithin, with a phosphate buffer saline $\mathrm{Na}_{2} \mathrm{HPO}_{4}-\mathrm{KH}_{2} \mathrm{PO}_{4}-\mathrm{NaCl}$ (PBS) solution, at physiological $p \mathrm{H}$ (7.4), according to the method of Barbinta-Patrascu et al. [22]. The resulted multilamellar lipid vesicles $(0.5 \mathrm{mM})$ were denoted "L".

An appropriate volume of a 200 fold diluted stock solution of vitamin C $0.05 \mathrm{~g} / \mathrm{mL}$, was inserted into $15 \mathrm{~mL}$ suspension of the as-prepared soybean lecithin liposomes, by ultrasound assisted treatment (5 min. three times, on ultrasound bath Elmasonic $\mathrm{S} 60 \mathrm{H}$ ) resulting in lipid vesicles loaded with vitamin C (sample LC). During sonication steps, the liposomes undergo a structural reorganization, because the lipid membranes are broken and then re-assembled, resulting smaller vesicles, thus 
incorporating the dispersing medium containing vitamin $\mathrm{C}$. The final concentration of vitamin $\mathrm{C}$ in liposomal suspension was $11.9 \mu \mathrm{g} / \mathrm{mL}$. It should be mentioned that vitamin $\mathrm{C}$ is water-soluble drug, so it is found both in the aqueous interior of liposomes and in the dispersed aqueous environment of these lipid vesicles.

\subsubsection{Preparation of silver-based biocomposites}

In this paper we designed for the first time silver-based composites based on liposomes, vitamin $\mathrm{C}$, and AgNPs synthesized from burdock, with two silver:liposomes ratios. The biocomposites were prepared by ultrasonic irradiation (15 minutes with breaks, on ultrasound bath Elmasonic $\mathrm{S} 60 \mathrm{H}$ ) of a mixture containing burdock-derived AgNPs (nS) and liposomes (L or LC) in a volumetric ratio of 1:1 and 2:1, resulting in 4 types of composites: $\mathrm{nSL1}, \mathrm{nSL2}, \mathrm{nSLC1}$ and $\mathrm{nSLC} 2$.

In addition, liposomes confer stability and protection to the components of biocomposites: AgNPs and vitamin C. Marsanasco et al. highlighted the protective role of liposomes as vehicles for vitamins $\mathrm{E}$ and $\mathrm{C}$ [23].

In previous studies, TEM images showed that the silver nanoparticles are coated with liposomes [4], and could be located both in the intervesicular medium and in the vesicular multilamellar structures [24].

A summary presentation of all the samples obtained together with their abbreviations is shown in Table 1.

Table 1. The abbreviations of the obtained samples

\begin{tabular}{|c|c|}
\hline Sample & Code \\
\hline Burdock extract & BE \\
\hline Nano-silver (AgNPs) phytogenerated from burdock extract & $\mathrm{L}$ \\
\hline Soybean lecithin MLVs & LC \\
\hline Soybean lecithin MLVs - vitamin C & $\mathrm{nSL} 1$ \\
\hline Liposomes/AgNPs biohybrids (1:1, v/v) & $\mathrm{nSL} 2$ \\
\hline Liposomes/AgNPs biohybrids (1:2, v/v) & $\mathrm{nSLC} 1$ \\
\hline Liposomes-vitamin C /AgNPs biohybrids $(1: 1, \mathrm{v} / \mathrm{v})$ & $\mathrm{nSC} 2$ \\
\hline
\end{tabular}

\subsection{Characterization methods}

The absorption spectra of the samples were recorded on a Jasco V-570 (LSE-331) double beam UVVis spectrophotometer, operating at $1 \mathrm{~nm}$ resolution, in the 200-600 nm wavelength range.

Dynamic Light Scattering (DLS) method (Zetasizer Nano ZS, Malvern Instruments Ltd., U.K.) was used to evaluate the average size, $Z_{\mathrm{av}}$, of the particles (the particle diameter plus the double-layer thickness), and also the polydispersity index, PdI. The samples were analysed as previously described [25]. The mean values \pm standard deviations of $\mathrm{Z}_{\mathrm{av}}$ and $\mathrm{PdI}$ were reported for each sample, from three different measurements.

Zeta potential $(\mathrm{ZP}, \mathrm{mV})$ measurements were performed in triplicate, with a special dispositive of Zetasizer Nano ZS (Malvern Instruments Ltd., UK) by applying an electric field across the tested aqueous suspensions.

\section{Estimation of antioxidant activity by chemiluminescence method}

The antioxidant properties of the samples were checked by chemiluminescence technique, by using luminol-based free radical generator system (containing $10^{-3} \mathrm{M}$ luminol, $10^{-5} \mathrm{M} \mathrm{H}_{2} \mathrm{O}_{2}$, in TRIS-HCl buffer solution $\mathrm{pH}$ 8.6), according to [26]. The in vitro antioxidant activity (AA\%) values were calculated from three different determinations, by using the following equation:

$$
\mathrm{AA} \%=\left[\left(\mathrm{I}_{0}-\mathrm{I}\right) / \mathrm{I}_{0}\right] \cdot 100 \% \%
$$

where $I_{0}$ and $I$ are the maximum CL intensities at $\mathrm{t}=5 \mathrm{~s}$, for the standard and for each sample, respectively. 


\section{Results and discussions}

\subsection{Spectral characterization of silver-based composites}

UV-Vis absorption spectroscopy and Dynamic Light Scattering measurements were used to demonstrate the formation of silver nanoparticles and silver-based composite systems.

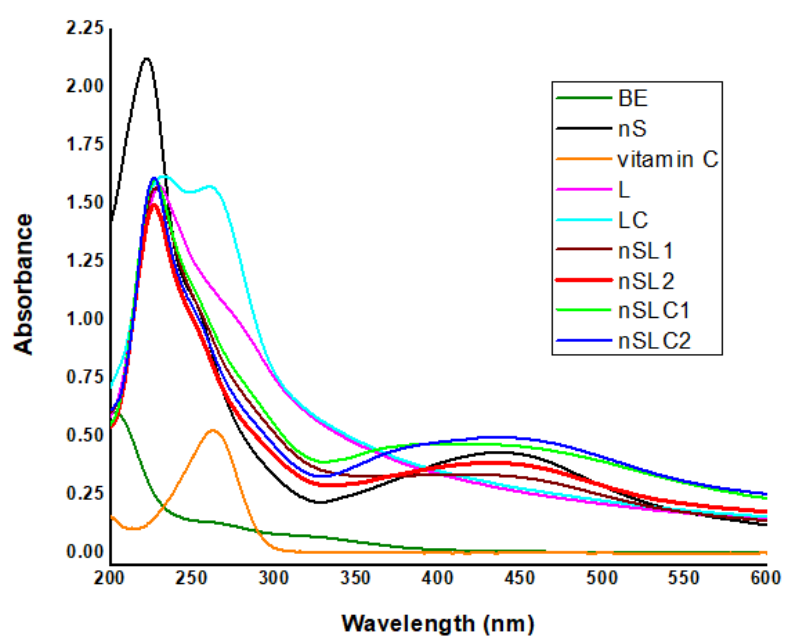

Figure. 1. Comparative

$\mathrm{UV}$-Vis absorption spectra of the obtained samples

The UV-Vis absorption spectrum of AgNPs "green" synthesized from Arctium lappa leaves (sample $\mathrm{nS}$ in Figure 1) showed a strong SPR peak located at $437 \mathrm{~nm}$ wavelength (peak not present in the $\mathrm{BE}$ spectrum), occurring after addition of burdock extract (BE) in $1 \mathrm{mM} \mathrm{AgNO}_{3}$ solution, thus demonstrating the biosynthesis of silver nanoparticles.

The characteristic peak of vitamin C located at $263 \mathrm{~nm}$ was shifted to $259 \mathrm{~nm}$ in absorption spectrum of liposomes LC.

The spectral fingerprint of AgNPs in silver-based biocomposites was blue-shifted from $437 \mathrm{~nm}$ (for $\mathrm{nS}$ ) to $409 \mathrm{~nm}$ for nSL1, $431 \mathrm{~nm}$ for nSL2, $417.5 \mathrm{~nm}$ for nSLC1, and $435 \mathrm{~nm}$ for nSLC2, confirming the synthesis of biocomposites. These shifts are more pronounced for samples nSL1 and nSLC1, with liposomes:AgNPs ratio of $1: 1(\mathrm{v} / \mathrm{v})$ as compared to the samples with liposomes:AgNPs ratio of 1:2 (v/v). On the other hand, it could be observed that absorption spectra of composites containing ascorbic acid display a slight blue shift. This different behaviour could be explained by a different structural organization of biocomposites loaded with vitamin $\mathrm{C}$.

The presence of vitamin $\mathrm{C}$ and AgNPs in liposome-based biocomposites was demonstrated by the presence of spectral signatures of AgNPs and vitamin C in the UV-Vis absorption spectra of liposomebased biocomposites, as well as through the "shifts" of these "spectral fingerprints".

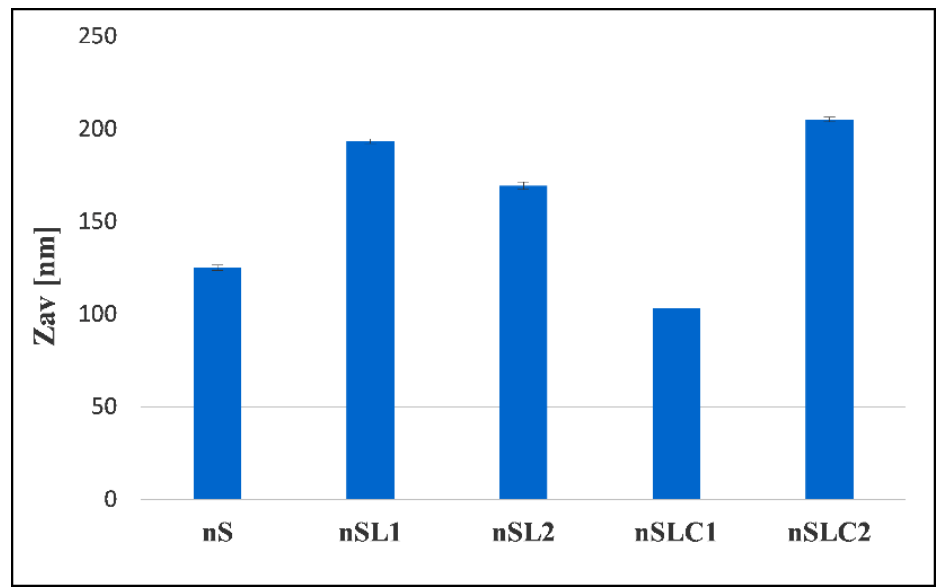

Figure 2. The mean size values of silver-based composites 
Mean diameter of nanoparticles estimated by DLS measurements (Fig. 2) ranged from 103 to 194.5 $\mathrm{nm}$. Among all developed biocomposites, those containing burdock-nanosilver and bio-inspired membranes loaded with vitamin $\mathrm{C}(1: 1, \mathrm{v} / \mathrm{v})$ presented the smallest size, with a mean diameter of 103 $\mathrm{nm} \pm 4.25$ (Figure 2).

\subsection{Estimation of physical stability of bio-based composites}

The physical stability of the bio-based composites was estimated in terms of zeta potential, ZP (Fig. 3), based on electrophoretic mobility; ZP value is related to the surface particle charge [27].

All the samples presented a negative surface charge that induces repulsive forces among particles (Fig. 3), assuring short-term stability for nanosilver $\mathrm{nS}(\mathrm{ZP}=-17 \mathrm{mV})$ and liposomes $\mathrm{L}(\mathrm{ZP}=-20.45$ $\mathrm{mV}$ ), and good stability for the other samples as well. Samples loaded with ascorbic acid have more negative ZP values, therefore they are more stable.

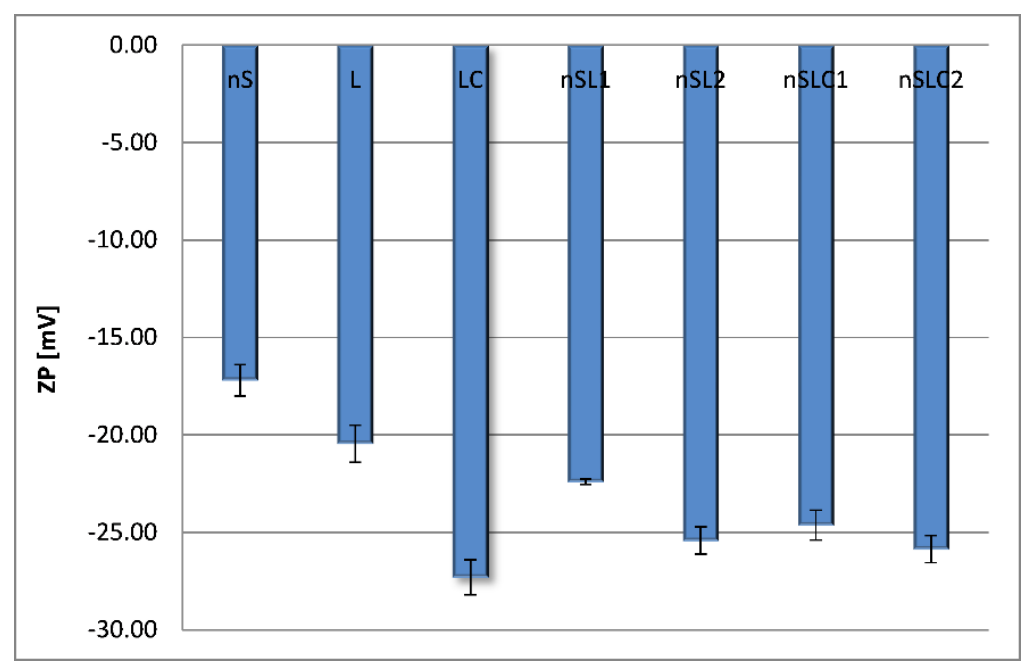

Figure. 3. Zeta potential values of the burdock-nanosilver, liposomes, and their biocomposites

Liposomal formulation of vitamin $\mathrm{C}$ showed good stability as compared to liposomes alone $\left(\mathrm{ZP}_{\mathrm{LC}}=-27.3 \mathrm{mV} ; \mathrm{ZP}_{\mathrm{L}}=-20.45 \mathrm{mV}\right)$. Thus, addition of vitamin $\mathrm{C}$ resulted in enhancing the $\mathrm{ZP}$ magnitude, from $|-22.4| \mathrm{mV}$ to $|-24.63| \mathrm{mV}$ for systems containing AgNPs and liposomes in a ratio of $1: 1, \mathrm{v} / \mathrm{v}$, and from $|-25.43| \mathrm{mV}$ to $|-25.85| \mathrm{mV}$ for systems containing AgNPs and liposomes in a ratio of 2:1, v/v. Combination of biomimetic membranes with burdock-derived silver nanoparticles (nS) assured an enhancement of physical stability of $\mathrm{nS}$. These results are in agreement with our previous works [4-7].

\subsection{Evaluation of antioxidant activity of silver-based bionanosystems generated from Arctium lappa leaves}

The antioxidant properties of the samples were tested through chemiluminescence technique, and the values of AA\% (calculated using equation 1) are comparatively displayed in Fig.4.

The "green" synthesized silver nanoparticles, $\mathrm{nS}$, presented high value of antioxidant activity: $89.3 \%$, and the liposomal formulations of vitamin $\mathrm{C}$ showed an AA\% value of $72.3 \%$, greater than liposomes alone $(\mathrm{AA} \%=47.8 \%)$. The biogenic silver nanoparticles, $\mathrm{nS}$, exhibited an amplified value of antioxidant activity (89.3\%) as compared to vegetal extract alone (83\%), this amplification being assessed to the nano-scaled size of metallic nanoparticles which offers an increase in total surface area providing many reaction centers for free radical scavenging [7]. This enhancement of AA\% value was highlighted also in our previous studies $[4,7]$. 
Moreover, the presence of ascorbic acid gave rise to biosystems with enhanced antioxidant activities (83\% and $88 \%$ for $\mathrm{nSLC} 1$ and $\mathrm{nSLC} 2$, respectively) as compared to liposomes free of vitamin C (75\% and $85 \%$ for $\mathrm{nSL} 1$ and $\mathrm{nSL} 2$, respectively).

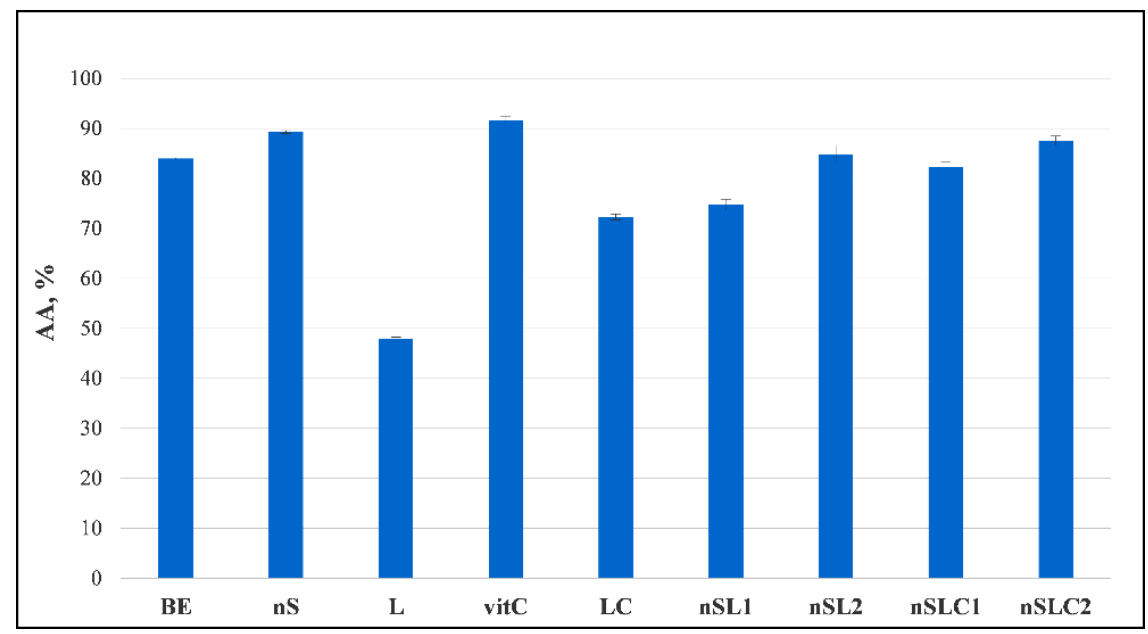

Figure 4. The antioxidant activity of the obtained silver-based bionanosystems generated from Arctium lappa leaves

Even in dilution of 1.5 or 2 fold, in lipid vesicles, the silver nanoparticles bio-generated from burdock exhibited high antioxidant activity. The AA\% values of silver - based composites containing vitamin $\mathrm{C}$, developed in this study, are higher than for nanosilver/lecithin - biocomposites derived from Geranium (72\% [14]) and sage (86.5\% [28]).

The antioxidative potential of burdock-derived nanoparticles is conferred by the presence of antioxidant biocomponents in the burdock leaf composition: flavone derivatives (such as rutin, quercetin, luteolin, crocin, and cyanine) and polyphenol carboxylic acids (such as chlorogenic and caffeic acids) $[15,29]$.

\section{Conclusions}

Artificial cell membranes and phytogenic silver nanoparticles "green" generated from Arctium lappa extract were used to bottom-up design of antioxidant biogenic systems with and without vitamin C. UV-Vis absorption spectra demonstrated the formation of burdock-generated silver nanoparticles and their composites with bio-inspired lipid membranes loaded or not with ascorbic acid. DLS measurements displayed the nano-scaled size of the developed silver - based composite systems.

The shifts of spectral fingerprints of vitamin C and "green" silver nanoparticles in the UV-Vis absorption spectra of liposome-based biocomposites proved the presence of AgNPs and vitamin $\mathrm{C}$ in the obtained biocomposites.

The addition of vitamin $\mathrm{C}$ in biocomposites improved the properties of the obtained materials. Thus, silver-based systems containing vitamin $\mathrm{C}$ are more stable than silver-loaded systems without vitamin $\mathrm{C}$, so bio-based systems containing vitamin $\mathrm{C}$ showed enhanced physical stability as compared to systems without vitamin C (the increase was $33.5 \%$ for liposomes alone, $10 \%$ for biocomposites with liposomes:AgNPs ratio of 1:1, v/v, and 1.7\% for biocomposites with liposomes:AgNPs ratio of $1: 2, \mathrm{v} / \mathrm{v})$. In addition, the insertion of vitamin $\mathrm{C}$ in the burdock-derived silver-based composites significantly improved the antioxidant efficiency of such composites.

The liposomal components of biocomposites developed in our study, assured an enhancement of "green" nanosilver stability.

These developed materials could be applied in biomedical field as free radical scavenger, and as adjuvants in treatment of oxidative stress - related diseases. 
Acknowledgments: The present study was supported by the Projects JINR - Romania: The use of neutron diffraction and small angle scattering in geosciences (strong deformed gneisses and granites) and biology (hybrid bio-nano entities) (Theme No. 04-4-1121-2015/2020), and Structural investigation of drug delivery systems consisting of biohybrids based on DNA, biomimetic membranes, "green" nanometals and therapeutic agents (Theme No. 04-4-1141-2020/2022).

\section{References}

1. SERRANO, G, ALMUdÉVER, P., SERRANO, J.-M., MILARA, J., TORRENS, A., EXPÓSITO, I., CORTIJO, J., Phosphatidylcholine liposomes as carriers to improve topical ascorbic acid treatment of skin disorders, Clin. Cosmet. Investig. Dermatol., 8, 2015, 591-599.

2. BARBINTA-PATRASCU, M.E., TUGUlEA, L., MEGHEA, A., Procaine effects on model membranes with chlorophyll $a$, Rev. Chim., 60 (4), 2009, 337-341.

3. STEFANESCU, T., MANOLE, C., PARVU, C., BARBINTA-PATRASCU, M.E., TUGULEA, L., Supported phospholipid bilayers with chlorophyll for optoelectronic devices, Optoelectron. Adv. Mat., 4(1), 2010, 33-38.

4. BARBINTA-PATRASCU, M.E., BADEA, N., BACALUM, M., UNGUREANU, C., SUICABUNGHEZ, I.R, IORDACHE, S.M., PIRVU, C., ZGURA, I., MARALOIU, A.V., 3D hybrid structures based on biomimetic membranes and Caryophyllus aromaticus - "green" synthesized nanosilver with improved bioperformances, Mat. Sci. Eng. C., 101, 2019, 120-137.

5. BARBINTA-PATRASCU, M.E, UNGUREANU, C., SUICA-BUNGHEZ, I.-R., IORDACHE, A.M., MILENKOVIĆ PETROVIĆ, S., ISPAS, A., ZGURA, I., Performant silver-based biohybrids generated from orange and grapefruit wastes, J. Optoelectron. Adv. Mat., 20(9-10), 2018, 551-557.

6. BARBINTA-PATRASCU, M.E., BADEA, N., PIRVU, C., BACALUM, M., UNGUREANU, C., NADEJDE, P.L., ION, C., RAU, I., Multifunctional soft hybrid bio-platforms based on nano-silver and natural compounds, Mat. Sci. Eng. C, 69, 2016, 922-932.

7. BARBINTA-PATRASCU, M. E., BADEA, N., UNGUREANU, C., CONSTANTIN, M., PIRVU, C., RAU, I., Silver-based biohybrids "green" synthesized from Chelidonium majus L., Opt. Mat., 56, 2016, 94-99.

8. BUMBAC, M., OLTEANU, R.L., ION, R.M., NICOLESCU, C.M., Influence of Temperature on the Growth of Silver Nanoparticles Synthesized Using Salvia officinalis Aqueous Extract, Rev. Chim., 69(8), 2018, 1934-1938.

9. CORCIOVA, A., BURLEC, A.F., GHELDIU, A.M., FIFERE, A., LUNGOCI, A.L., MARANGOCI, N., MIRCEA, C., Biosynthesis of Silver Nanoparticles Using Licorice Extract and Evaluation of their Antioxidant Activity, Rev. Chim., 70(11), 2019, 4053-4056.

10. BARBINTA-PATRASCU, M.E., BADEA, N., BACALUM, M., ANTOHE, S., Novel bio-friendly nanomaterials based on artificial cell membranes, chitosan and silver nanoparticles phytogenerated from Eugenia caryophyllata buds: eco-synthesis, characterization and evaluation of bioactivities, Rom.Rep.Phys., 72(1), 2020, 601.

11.BARBINTA-PATRASCU, M.E., CONSTANTIN, M., BADEA, N., UNGUREANU, C., IORDACHE, S.M., PURCAR, V., ANTOHE, S., Tangerine-Generated Silver - Silica Bioactive Materials, Rom. J. Phys., 64(3-4), 2019, 701.

12. BARBINTA-PATRASCU, M.E., BADEA, N., CONSTANTIN, M., UNGUREANU, C., NICHITA, C., IORDACHE, S.M., VLAD, A., ANTOHE, S., Bio-activity of organic/inorganic phytogenerated composites in bio-inspired systems, Rom. J. Phys, 63(5-6), 2018, 702.

13. PROKS, M., BORCAN, F., CHEVERESAN, A., PINZARU, I., GUTA, B.A., CORICOVAC, D., PAUNESCU, V., LAZUREANU, V., Study on the Release and Bioevaluations of Green Silver Nanoparticles Entrapped Inside Polymer-based Nanovesicles, Mater. Plast., 55(4), 2018, 696-699.

14. BARBINTA-PATRASCU, M.E., BADEA, N., UNGUREANU, C., BUNGHEZ, R.I., RAU, I., Gold and silver geranium biocomposites, Mol. Cryst. Liq. Cryst., 627(1), 2016, 190-197. 
15. IONESCU, D., POPESCU, M., RIZEA, G.D., MIHELE, D., BUlEARCA, G., IVOPOL, M., MIHALCEA, F., Polyphenols and Minerals, Antioxidants in the Plants Used in the Natural Treatment of Hepatobiliary Disorders, Rev. Chim., 65(5), 2014, 507-511.

16. BARBINTA-PATRASCU, M.E., BADEA, N., UNGUREANU, C., BESLIU, D., ANTOHE, S., Bioactive phyto-nanosilver particles "green" synthesized from Clary Sage, Burdock, Southernwood and Asparagus, Rom. Rep. Phys., 2020 (in press).

17. LACATUSU, I., ARSENE, L.V., BADEA, G., POPA, O., OPRE, O., BADEA, N., New cosmetic formulations with broad photoprotective and antioxidative activities designed by amaranth and pumpkin seed oils nanocarriers, Ind. Crops Prod., 123, 2018, 424-433.

18. LACATUSU, I., BADEA, N., BADEA, G., BRASOVEANU, L., STAN, R., OTT, C., OPREA, O., MEGHEA, A., Ivy leaves extract based-lipid nanocarriers and their bioefficacy on antioxidant and antitumor activities, $R S C A d v$., 6(81), 2016, 77243-77255.

19. VOICESCU, M., NISTOR, C.L., MEGHEA, A., Insights into the antioxidant activity of some flavones on silver nanoparticles using the chemiluminescence method, J. Lumin., 157, 2015, 243-248.

20. PADAYATTY, S.J., KATZ, A., WANG, Y., ECK, P., KWON, O., LEE, J.H., CHEN, S., CORPE, C., DUTTA, A., DUTTA, S.K., LEVINE, M., Vitamin C as an antioxidant: evaluation of its role in disease prevention, J. Am. Coll. Nutr., 22(1), 2003, 18-35.

21. MAIONE-SILVA, L., DE CASTRO, E.G., NASCIMENTO, T.L., CINTRA, E.R., MOREIRA, L.C., CINTRA, B.A.S., VALADARES, M.C., LIMA, E.M., Ascorbic acid encapsulated into negatively charged liposomes exhibits increased skin permeation, retention and enhances collagen synthesis by fibroblasts, Sci. Rep., 9, 2019, 522.

22. BARBINTA-PATRASCU, M.E., IORDACHE, S.M., IORDACHE, A.M., BADEA, N., UNGUREANU, C., Nanobioarchitectures based on chlorophyll photopigment, artificial lipid bilayers and carbon nanotubes, Beilstein J. Nanotechnol., 5, 2014, 2316-2325.

23. MARSANASCO, M., MÁRQUEZ, A.L., WAGNER, J.R., ALONSO, S.D.V., CHIARAMONI, N.S., Liposomes as vehicles for vitamins $E$ and $C$ : An alternative to fortify orange juice and offer vitamin C protection after heat treatment, Food Res. Int., 44, 2011, 3039-3046.

24. CASTANGiA, I., MARONGIU, F., MANCA, M.L., POMPEI, R., ANGIUS, F., ARDU, A., FADDA, A.M., MANCONI, M., ENNAS, G., Combination of grape extract-silver nanoparticles and liposomes: A totally green approach, Eur. J. Pharm. Sci., 97, 2017, 62-69.

25. BARBINTA-PATRASCU, M.E., Biohybrids based on DNA and bio-inspired lipid membranes: design and characterization, Optoelectron. Adv. Mat., 13 (9-10), 2019, 546-550.

26. BARBINTA-PATRASCU, M.E., BADEA, N., ŢUGULEA, L., GIURGINCA, M., MEGHEA, A., Oxidative stress simulation on artificial membranes- chemiluminescent studies, Rev. Chim., 59(8), 2008, 834-837.

27. MISHRA, P.R., AL SHAAL, L., MÜLLER, R.H., KECK, C.M., Production and characterization of Hesperetin nanosuspensions for dermal delivery, Int. J. Pharm., 371, 2009, 182-189.

28. BARBINTA-PATRASCU, M.E., BUNGHEZ, I.R., IORDACHE, S.M., BADEA, N., FIERASCU, R.C., ION, R.M., Antioxidant Properties of Biohybrids Based on Liposomes and Sage Silver Nanoparticles, J. Nanosci. Nanotechnol., 13(3), 2013, 2051 - 2060.

29. LOU, Z., TANG, Y., SONG, X., WANG, H., Metabolomics-Based Screening of BiofilmInhibitory Compounds against Pseudomonas aeruginosa from Burdock Leaf, Molecules, 20, 2015, p. 16266-16277.

$\overline{\text { Manuscript received: } 29.02 .2020}$ 